\title{
Abnormal osteocalcin binding in rheumatoid arthritis
}

\author{
Angela Fairney, K V Patel, N P Hollings, M H Seifert
}

\begin{abstract}
Studies of osteocalcin in the serum and synovial fluid of patients with rheumatoid arthritis (RA) and osteoarthritis (OA) showed the presence of significant amounts of osteocalcin in synovial fluid and that the values in RA synovial fluid were significantly lower than in OA synovial fluid. In addition, the osteocalcin in OA synovial fluid bound almost completely to hydroxyapatite, whereas a significant proportion of the osteocalcin in RA synovial fluid did not. These studies suggest that patients with severe RA produce low amounts of active osteocalcin and higher than expected amounts of inactive osteocalcin in the synovial fluid. They provide some evidence that osteoblast function may be abnormal in the osteoporosis of RA.
\end{abstract}

Osteoporosis is a common clinical problem in patients with rheumatoid arthritis (RA). The exact pathogenesis of this type of bone disease is unknown, but one possible explanation is an abnormality of osteoblast function or secretion.

Osteocalcin (bone $\gamma$-carboxyglutamic acid (Gla) protein) is a vitamin $\mathrm{K}$ dependent protein, which is a specific product of the osteoblast. ${ }^{1}$ The osteocalcin found in serum comes from new cellular synthesis rather than from the release of bone matrix protein during bone resorption $^{2}$ and it contains three residues of glutamic acid, which are carboxylated to form carboxyglutamic acid. This carboxylated form of osteocalcin is thought to be the active form of the protein as it binds strongly to hydroxyapatite. $^{3}$

Studies of bone status in patients with RA have shown varying results for osteocalcin measurements. Several studies have shown reduced mean serum osteocalcin values in $R A,{ }^{4} 5$ suggesting reduced bone formation. Another study found no relation between serum osteocalcin and the inflammatory activity of the arthritis, ${ }^{6}$ and a further report described increased values of serum osteocalcin in RA, suggesting increased bone turnover. ${ }^{7}$ These different results may reflect heterogeneity of bone involvement, the effect of different types of treatment, or methodological differences in the osteocalcin assay.

The radioimmunoassays at present in use for measurement of osteocalcin do not distinguish between the carboxylated (active) and noncarboxylated (inactive) forms of osteocalcin. It is therefore unknown whether the reports mentioned above are describing the fully carboxylated form or otherwise. The two forms of osteocalcin may be distinguished as carboxylated osteocalcin binds to hydroxyapatite whereas non-carboxylated osteocalcin does not. ${ }^{2} \mathrm{We}$ therefore determined the total and nonhydroxyapatite-bound osteocalcin in the serum and synovial fluid of patients with RA and in patients with osteoarthritis (OA) for comparison.

\section{Patients and methods}

Paired serum and synovial fluid samples were collected from 11 patients with RA and 13 patients with $\mathrm{OA}$ attending the outpatient rheumatology clinic for therapeutic knee aspiration. The samples were stored at $-20^{\circ} \mathrm{C}$ before assay for osteocalcin and $\mathrm{C}$ reactive protein. Osteocalcin was measured by radioimmunoassay (CIS (UK), Wycombe, Bucks) and C reactive protein by LC-Partigen immunodiffusion plates (Behring Diagnostics, Hounslow, Middlesex). Binding of osteocalcin to hydroxyapatite was determined in nine pairs of samples from patients with $\mathrm{OA}$ and in 10 sample pairs from patients with RA, as described by Price $e t a l .^{2}$

Serum or synovial fluid for osteocalcin measurement was divided into two portions. One aliquot was extracted with hydroxyapatite ( $20 \mathrm{mg}$ to $200 \mu \mathrm{l}$ serum or synovial fluid), the mixture vortexed, turned end over end at $4^{\circ} \mathrm{C}$ for 30 minutes, and centrifuged for five minutes in a table top clinical centrifuge. The resulting supernatant containing non-hydroxyapatitebound osteocalcin and the other aliquot containing the total amount of osteocalcin were assayed for osteocalcin in the same radioimmunoassay. The hydroxyapatite bound osteocalcin was obtained by subtraction, and the lower limit of sensitivity for osteocalcin was $0.35 \mathrm{ng} / \mathrm{ml}$.

\section{Results}

Significant amounts of total osteocalcin were detected in the synovial fluid, and dilution of synovial fluid samples showed linearity when the osteocalcin values were compared with those in serum. The serum total osteocalcin values in RA and OA were normal (5.8 (SD 2.08) and 6.5 $(2 \cdot 5) \mathrm{ng} / \mathrm{ml}$ respectively), whereas the values in RA synovial fluid were significantly lower than those in OA synovial fluid (3.24 (2.05) and 5.1 $(2 \cdot 1) \mathrm{ng} / \mathrm{ml}$ respectively, $\mathrm{p}<0 \cdot 04)$.

Up to $25 \%$ of the osteocalcin in normal, OA, and RA serum did not bind to hydroxyapatite. The osteocalcin in OA synovial fluid, however, bound almost completely to hydroxyapatite $(0-1.9 \%$ unbound), whereas a significant proportion of the osteocalcin in RA synovial fluid 


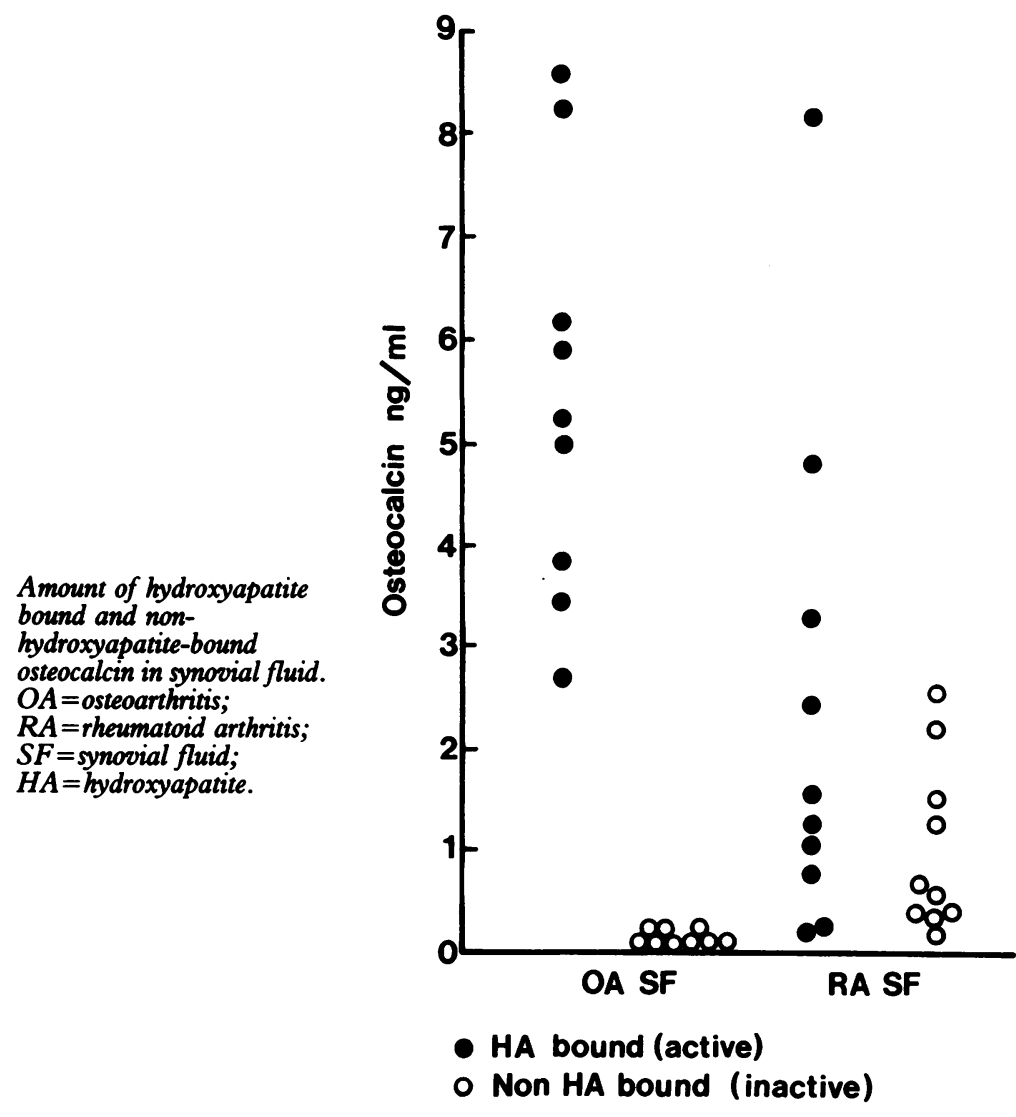

(0-92\% unbound) did not. The carboxylated form of osteocalcin, therefore, was present in similar concentrations in OA synovial fluid and serum. The RA synovial fluid osteocalcin, on the other hand, was present at a concentration about half that in serum, and in some patients with RA the synovial fluid contained significant amounts of osteocalcin that were not fully carboxylated (inactive) (figure). In addition, RA synovial fluid contained measurable amounts of $C$ reactive protein, whereas $O A$ synovial fluid did not. High $C$ reactive protein values were found in samples of synovial fluid containing high amounts of non-hydroxyapatite-bound osteocalcin $(r=0.77, p<0.01)$.

\section{Discussion}

To our knowledge this is the first report of hydroxyapatite binding studies on the osteocalcin found in synovial fluid. The interpretation of synovial fluid values in arthritis is difficult because normal synovial fluid is not freely available for comparison. Previous work from our laboratory has shown that substances such as 25-hydroxyvitamin D and retinol are present in synovial fluid at approximately half the concentration of that in serum in both RA and OA. ${ }^{89}$ Thus the RA synovial fluid values for total osteocalcin we obtained are of the order expected, whereas the values obtained in OA synovial fluid are higher than expected. The latter may reflect new bone formation within the joint.

The values of osteocalcin obtained after hydroxyapatite binding in RA synovial fluid are particularly interesting as they suggest that patients with severe RA produce low amounts of active osteocalcin and higher than expected amounts of inactive osteocalcin in their synovial fluid. The origin of synovial fluid osteocalcin is not clear. It may be derived from the circulation and thus represent new synthesis from osteoblasts, or possibly from break down of bone surrounding the joint. The relation between $\mathrm{C}$ reactive protein and the non-hydroxyapatitebound osteocalcin suggests, however, that the rheumatoid process may interfere with normal binding of osteocalcin to bone, and contribute to the pathogenesis of osteoporosis in RA.

Another possible explanation may be defective vitamin $\mathrm{K}$ activity as low concentrations of serum vitamin $K$ have been found in patients with osteoporosis. ${ }^{10}$ Osteocalcin is vitamin $\mathrm{K}$ dependent and patients receiving vitamin $K$ antagonists, such as phenprocoumon, have higher than normal amounts of inactive osteocalcin in their serum. ${ }^{11}$ As the serum osteocalcin in our patients showed normal hydroxyapatite binding it is unlikely that the patients were deficient in vitamin $K$. In view of the higher amounts of non-hydroxyapatite-bound osteocalcin in RA synovial fluid than in OA synovial fluid, however, it is possible that synovial vitamin $K$ activity is defective in patients with RA.

A further possibility relates to synovial fibroblast metabolism. The cells that comprise the pannus in RA are also exposed to local hormones or hormones carried to the site by the circulation-for example, parathyroid hormone. Parathyroid hormone has its primary action on target cells in bone-for example, osteoblasts, but it also stimulates the production of cAMP from synovial cells in culture. As parathyroid hormone stimulates bone resorption, increased sensitivity of synovial fibroblasts to its effects might be an additional factor producing connective tissue destruction and subsequent release of osteocalcin into the joint. ${ }^{12}$

We are grateful to the Joint Standing Research Committee of St Mary's Hospital for financial support.

1 Lian J B, Gundberg C M. Osteocalcin-biochemical considerations and clinical applications. Clin Orthop 1988; 226: 267-91.

2 Price P A, Williamson M K, Lothringer J W. Origin of the vitamin-dependent bone protein found in plasma and its vitamin-dependent bone protein found in plasma and its clearance

3 Poser J W, Price P A. A method for decarboxylation of $\gamma$-carboxyglutamic acid in protein. $\mathcal{F}$ Biol Chem 1979; 254 431-6.

4 Orth R W, Weisman M H, Catherwood B D, Manolagas S C, Deftos L J. Bone loss in rheumatoid arthritis. Arthritis Rheum 1983; 26: Abstract 120.

5 Sambrook P N, Ansell B M, Foster S, et al. Bone turnover in early rheumatiod arthritis. 1. Biochemical and kinetic indexes. Ann Rheum Dis 1985; 44: 575-9.

6 Ekenstam E A, Ljunghall S, Hallgren R. Serum osteocalcin in rheumatoid arthritis and other inflammatory arthritides: relation between inflammatory activity and the effect of glucocorticoids and remission inducing drugs. Ann Rheum Dis 1986; 45: 484-90.

7 Gevers G, Devos P, De Roo M, Dequeker J. Increased levels of osteocalcin (serum bone gla protein) in rheumatoid of osteocalcin (serum bone gla protein)

8 Fairney A, Straffen A M May C, Seifert M H. Vitamin D metabolites in synovial fluid. Ann Rheum Dis 1987; 46: $370-4$.

9 Fairney A, Patel K V, Fish D E, Seifert M H. Vitamin A in Fairney A, Patel K V, Fish D E, Seifert M H. Vitamin A in osteo and

10 Hart J P, Shearer M J, Klenerman L, et al. Electrochemical detection of depressed circulating levels of vitamin $K_{1}$ in osteoporosis. F Clin Endocrinol Metab 1985; 60: 1268-9.

11 Pietschmann P, Woloszczuk W, Panzer S, Kyrle P, Smolen . Decreased serum osteocalcin levels in phenprocoumon treated patients. F Clin Endocrinol Metab 1988; 66: 1071-4.

12 Krane S M. Aspects of the cell biology of the rheumatoid synovial lesion. Ann Rheum Dis 1981; 40: 433-48. 